\title{
Surface water quality contamination source apportionment and physicochemical characterization at the upper section of the Jakara Basin, Nigeria.
}

\begin{abstract}
The present study investigates the surface water quality of three important tributaries of Jakara Basin, northwestern Nigeria to provide an overview of the relationship and sources of physicochemical and biological parameters. A total of 405 water samples were collected from 27 sampling points and analyzed for 13 parameters: dissolved oxygen (DO), 5-day biochemical oxygen demand (BOD5), chemical oxygen demand (COD), suspended solids (SS), pH, ammonia-nitrogen (NH3NL), dissolved solids (DS), total solids (TS), nitrates (NO3), chloride (Cl), phosphates (PO4), Escherichia coli (E. coli) and fecal coliform bacteria (FCB). Pearson's product-moment correlation matrix and principal component analysis (PCA) were used to distinguish the main pollution sources in the basin. Four varimax components were extracted from PCA, which explained 84.86, 83.60, and $78.69 \%$ of the variation in the surface water quality for Jakara, Tsakama, and Gama-Kwari Rivers, respectively. Strong positive loading included BOD5, COD, NH3NL, E. coli, and FCB with negative loading on DO attribute to a domestic waste water pollution source. One-way ANOVA revealed that there was no significant difference in the mean of the three water bodies $(p>0.05)$. It is therefore recommended that the government should be more effective in controlling the point source of pollution in the area.
\end{abstract}

Keyword: Water quality; Principal component analysis; Correlation analysis; One-way analysis of variance. 